\title{
A STUDY OF BLOWING SNOW BY THE NEW INDEX
}

\section{Abstract}

by

\section{SeI-ITI SATo}

The School of Allied Medical Sciences, Hirosaki University, Hirosaki, Japan

Visual observation on the natural snow surface shows that the phenomenon of blowing snow changes by an index $P_{b}$. The phenomenon is related strongly to wind velocity $\mathrm{V}(\mathrm{m} / \mathrm{s})$ and air temperature $\mathrm{T}\left({ }^{\circ} \mathrm{C}\right)$. The index was set up by way of experiment as follows:

$$
P_{b}=a V-b T \text {. }
$$

Where $\mathrm{a}(\mathrm{s} / \mathrm{m})$ and $\mathrm{b}\left({ }^{\circ} \mathrm{C}^{-1}\right)$ are the coefficients, and the author assumes $\mathrm{a}=\mathrm{b}=1$. Then, the dimentionless equation $\mathrm{P}_{\mathrm{b}}$ called "blowing snow index" is defined:

$$
P_{b}=V-T \text {. }
$$

On the snow surface on Shonai Plain (Honshu, Japan) 152 visual observations of the phenomenon were carried out at 9:00 every day. Observation points were set up on the plain at Tsuruoka C., Hirata T., Uza T. and Amarume T. Results from these observations were classified in 3 groups, namely, no blowing snow, slightly blowing snow and heavy blowing snow.

Figure 1 shows the obtained numbers $\mathrm{n}$ of each group. In the group of no blowing snow, the mean $P_{b}$ is 3.1. In

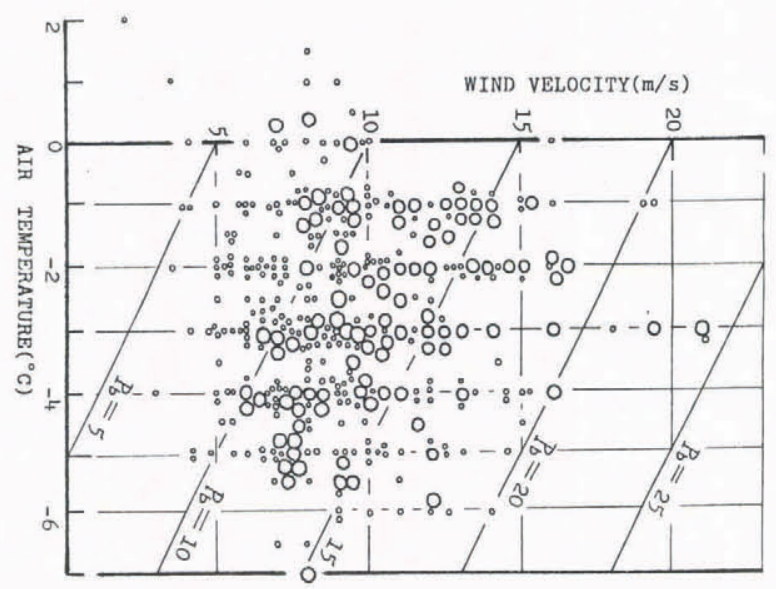

Fig.1. Grouping of observation numbers against $P_{b^{*}} A:$ no blowing snow, $P_{b}=3.1, B$ : slightly blowing snow, $P_{b}=$ $11.4, \mathrm{C}$ : heavy blowing snow, $\mathrm{P}_{\mathrm{b}}=14.2$.

the slightly and heavy groups, $P_{b}$ is 11.4 and 14.2 respectively. From the tendency shown on figure 1, it could be assumed that blowing snow phenomena do not happen in $P_{b}<7$, slightly blowing snow happens in $7 \leqslant P_{b}<12$, and heavy blowing snow happens in $12 \leqslant \mathrm{P}_{\mathrm{b}}$.

At the same places, the amount of blowing snow transport $\mathrm{Q}(\mathrm{g} / \mathrm{m} \cdot \mathrm{s})$ was measured 367 times. Values of $\mathrm{Q}$ were measured using a box blowing snow gauge. Up to this time, $Q$ had been written as follows:

$$
Q=0.03 V^{3}
$$

Now, the author attempts to write as:

$$
Q=\alpha P_{b}^{3}
$$

the mean values of $Q=16.4 \mathrm{~g} / \mathrm{m} \cdot \mathrm{s}$ and $P_{b}=12.1$ were obtained from those measurements.
The obtained $\alpha$ from those measurements have a wide range of fractuations. Then, the coefficient $\alpha$ is estimated as follows:

$$
\alpha=0.011 \pm 0.014
$$

The phenomenon of blowing snow depended remarkably on wind velocity, air temperature, degrees of hardness of a snow surface and diameters of snow particles. Therefore, it seems that to describe the tendency of the phenomenon by only $P_{b}$ is inadequate.

The obtained $Q s$ are grouped in accordance with $P_{b}$, namely, $Q<20 \mathrm{~g} / \mathrm{m} \cdot \mathrm{s}$ to $7 \leqslant \mathrm{P}_{\mathrm{b}}<12, Q \geqslant 20 \mathrm{~g} / \mathrm{m} \cdot \mathrm{s}$ to $12 \leqslant \mathrm{P}_{\mathrm{b}}$. Figure 2 shows the distribution of $Q$ as parametered by $P_{b}$.
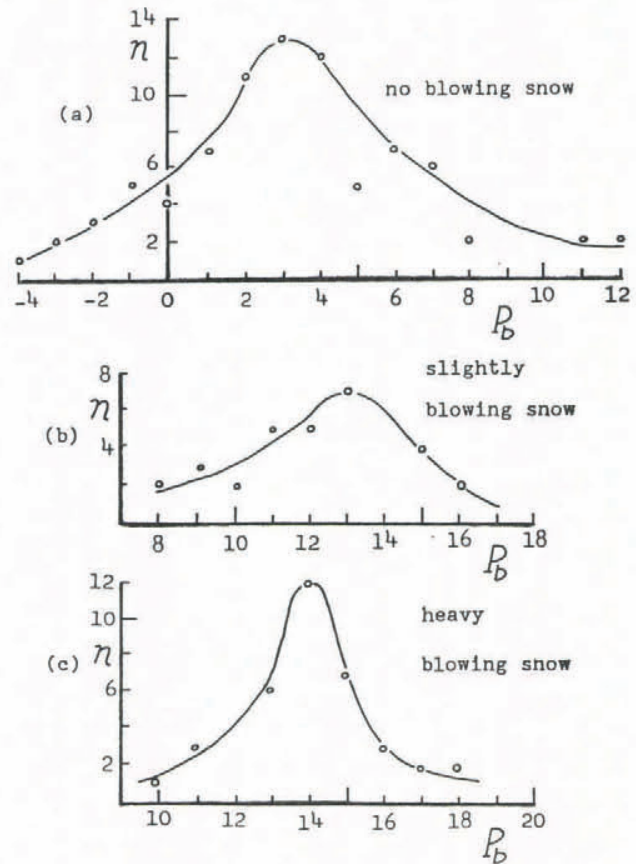

Fig.2. Distribution $Q$ against $P_{b}$; white small circles: $Q<20$ $\mathrm{g} / \mathrm{m} \cdot \mathrm{s}$, white large circles: $Q \geqslant 20 \mathrm{~g} / \mathrm{m} \cdot \mathrm{s}$.

The attempts to describe the initiation condition of blowing snow and the blowing snow transport $Q$ by the index $P_{b}$ are studied. The effectiveness of $P_{b}$ on blowing snow are summarized in the following: (1) On the condition $P_{b}<7$, the snow surface has no blowing snow, $7 \lessgtr P_{b}<12$ has slightly blowing snow and $12 \leqslant \mathrm{P}_{\mathrm{b}}$ has heavy blowing snow. (2) On the estimation of transportation, Q could be expressed as follows:

$$
Q=0.011 P_{b}^{3}
$$

but, the coefficient had wide ranging values.

In the particular case $7 \leqslant P_{b}<12$, the amount of snow transportation showed $\mathrm{Q}<20 \mathrm{~g} / \mathrm{m} \cdot \mathrm{s}$, and the other case, $12 \leqslant P_{b}$, showed $Q \geqslant 20 \mathrm{~g} / \mathrm{m} \cdot \mathrm{s}$. For these reasons, the index has a simple but useful characteristic on initiation condition of the blowing snow, but has little usefulness for the transport $Q$. 